\title{
Effect of Thin Cementitious Crust on the Mechanical Properties of Lightweight Pumice Aggregate Concrete
}

\author{
Karim, F. R*
}

Lecturer, College of Engineering, University of Sulaimani, Al-Sulaimanyah, Iraq

DOI: $10.36348 /$ SJCE.2019.v03i05.002

| Received: 02.09.2019 | Accepted: 09.09.2019 | Published: 16.09.2019

*Corresponding author: Dr. Ferhad Rahim Karim

\section{Abstract}

The porous surface of lightweight aggregate is the main weakness property for producing lightweight concrete. Thus, the filling porous in lightweight aggregate and creating thin layer surrounds aggregate produce stronger lightweight concrete. Therefore, the influence of silica fume and Sika level 100T on the tensile and compressive strengths of lightweight concrete is highlighted in this investigation. For this reason, it was cast and tested 84 lightweight concrete cubes and prisms. It was found that the compressive strength improves up to $22.73 \%$ and $34.57 \%$ due to inclusion $7.23 \%$ of silica fume and $9.6 \%$ of Sika level $100 \mathrm{~T}$, respectively. While the flexural strength enhances up to $5.4 \%$ and $25.72 \%$ due to adding $7.23 \%$ of silica fume and $9.6 \%$ of Sika level 100T, respectively. In addition, the curve fitting software was used in the formulation of the proposed models to verify this improvement and it was found that the proposed model has a good agreement with the test results.

Keywords: Lightweight concrete, Pumice, Silica fume, and Sika level 100T.

Copyright @ 2019: This is an open-access article distributed under the terms of the Creative Commons Attribution license which permits unrestricted use, distribution, and reproduction in any medium for non-commercial use (NonCommercial, or CC-BY-NC) provided the original author and source are credited.

\section{INTRODUCTION}

Lightweight aggregate is used to produce lightweight concrete when the weight of aggregate less than $1120 \mathrm{~kg} / \mathrm{m}^{3}$ [1]. Lightweight aggregates have many sources: natural materials such as pumice, volcanic cinders, etc. and artificial materials such as iron blast furnace slag, sintered fly ash [2-4]. The mechanical characteristics of the lightweight aggregate concrete strongly depend on the proportions of aggregate in the formulation [5].

All the porous aggregates have their characteristic properties, which markedly affect the properties of lightweight concrete. Among the lightweight concrete, pumice concrete generally considered as being unsuitable for load-bearing uses [6]. Thus, filling these pores on the surface of aggregate might produce higher strength, lightweight concrete capable of carrying loads.

Pumice stone is original of volcanic origin with bulk density in the region of 400 to $800 \mathrm{~kg}$ per cubic meter and produces concrete with a density of 450 to $1200 \mathrm{~kg}$ per cubic meter [7]. Besides, pumice aggregates meet the physical properties of concrete aggregates and can effectively be used as lightweight aggregates. The concrete which can be produced with these aggregates satisfies the requirements of low strength lightweight concrete [8].

\section{RESEARCH SIGNIFICANCE}

This paper highlights the influence of coating pumice aggregate by a thin cementitious crust on the compressive and tensile strengths of lightweight concrete including silica fume. Thus, this investigation conducts for filling the surface porous on pumice aggregates by cementitious materials and to investigate the physical properties of lightweight pumice concrete such as density and mechanical properties such as cube compressive strength and flexural strength.

\section{LITERATURE REVIEW}

Lightweight pumice aggregates have many pores on its surface, as shown in Figure-1. Thus, pumice aggregate coating with a thin cementitious crust appears to increase the workability of pumice aggregate self compacting concrete [9]. 


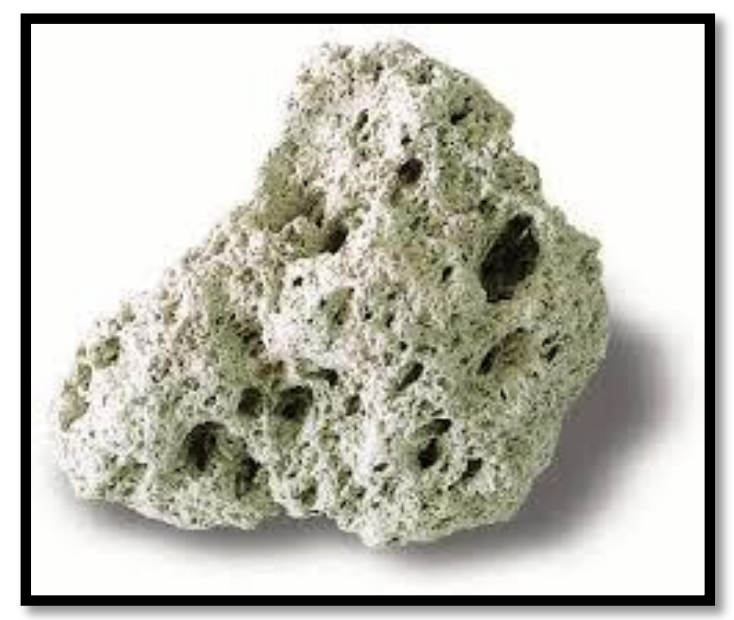

Fig-1: Surface porous on the pumice aggregate

Katkhuda and Shatarat [10] studied the influence of silica fume on high strength lightweight concrete. It has been used in this research the different percentage of silica fume $0,5,10,15,20$, and $25 \%$ for water-binder ratios ranging from 0.26 to 0.42 . It found that the highest increase indicated in the flexural strength, which reached $25 \%$, whereas the compressive strength improves in the range of $15 \%$ to $25 \%$.

Sivalingarao and Manju [7] studied the effect of silica fume on the mechanical properties of lightweight aggregate (pumice) concrete. In this research, the normal aggregate has replaced with a $100 \%$ pumice aggregate by volume, and for this replacements, cement is placed with silica fume in various proportions $(5,8,10,15$ and $20 \%)$ by weight. It found that the compressive strength, flexural strength, and the split tensile strength increase at $10 \%$ replacement of cement by silica fume.

Mohammadi et al., [11] studied the effect of silica fume on the properties of self-compacted lightweight concrete. In this study, water to binder ratio kept constant at 0.5 . It found that as the percentage of silica fume was increased from $5 \%$ to $15 \%$, the compressive strength and density become better for Lica and Perlite self-compacted lightweight concrete. Also, any increase in the percentage of silica fume, the density of concrete increases.

\section{EXPERIMENTAL WORKS}

Eighty-four cubes and prisms were cast to study the effect of coating the surface of pumice aggregate by a thin cementitious crust used in lightweight concrete containing silica fume.
The mix (C) is a control mix proportion which designed based on mix proportioning of structural lightweight aggregate concrete [12], and it created for 15.57MPa.

The percentage of silica fume is the first parameter in this investigation, with various proportions $5.797 \%, 7.237 \%$, and $8.696 \%$. While the second parameter based on the optimize silica fume percentage in the mix, the coating of pumice aggregate surface by Sika level 100T with various proportions $4.08 \%$, $9.615 \%$, and $14.54 \%$.

\section{MATERIALS, MIX PROPORTIONS, AND SPECIMEN PREPARATION}

In the following sections describe the materials and the mix proportion between ingredients for producing lightweight pumice aggregate concrete. Besides, the compressive and tensile testing procedures explained.

\section{MATERIALS AND MIX PROPORTION}

The target strength of lightweight pumice aggregate concrete was $15.57 \mathrm{MPa}$. For producing this lightweight concrete, ordinary Portland cement (Type I), Pumice aggregate with $19 \mathrm{~mm}$ maximum size, Pumice fine aggregate, silica fume, tap water, and Sika level 100T used. The mix proportion of these materials shown in Table-1. The physical properties of lightweight pumice aggregates and Silica fume and Sika level 100T used for fabricating 84 cubes and prisms in this research are tabulated in Tables 2 and 3, respectively.

Table-1: Mix proportioning of lightweight (Pumice) aggregate concrete

\begin{tabular}{|c|c|}
\hline Materials & Quality, kg/. \\
\hline Cement (Type I) & 430 \\
\hline Fine lightweight aggregate & 203.3 \\
\hline Coarse lightweight aggregate & 334.4 \\
\hline Water & 212.5 \\
\hline Slump, mm & 50 \\
\hline
\end{tabular}


Table-2: Physical properties of lightweight (Pumice) fine and coarse aggregates

\begin{tabular}{|c|c|c|}
\hline \multicolumn{2}{|c|}{ Lightweight fine aggregate } & Lightweight coarse aggregate \\
\hline Sieve analysis & $\%$ Pass & $\%$ Pass \\
\hline Sieve size, mm & - & 100 \\
\hline 25 & - & 94.78 \\
\hline 19 & - & 30.42 \\
\hline 12.5 & 100 & 13.45 \\
\hline 9.52 & 92.66 & 4.77 \\
\hline 4.76 & 70.09 & - \\
\hline 2.36 & 53.30 & - \\
\hline 1.18 & 38.48 & - \\
\hline 0.60 & 16.93 & - \\
\hline 0.30 & 5.10 & 16.65 \\
\hline 0.15 & 3.48 & 1.5 \\
\hline Water absorption & Moisture Content \\
\hline$\%$ of absorption & 2.4 & \\
\hline \multicolumn{2}{|c|}{} \\
\hline \% of moisture & \multicolumn{2}{|c|}{} \\
\hline
\end{tabular}

Table-3: Physical properties of Silica fume and Sika level 100T

\begin{tabular}{|c|c|c|}
\hline Properties & Silica fume & Sika level 100T \\
\hline Color & Gray powder & Standard grey powder \\
\hline Specific gravity & 2.26 & - \\
\hline Silicon dioxide, $\mathrm{SiO}_{2}, \%$ & 85 & - \\
\hline Chemical base & - & Polymer modified Portland cement \\
\hline Compressive strength at 28 days, $\mathrm{MPa}$ & - & 30 \\
\hline
\end{tabular}

\section{FABRICATION OF SPECIMENS}

The tilt mixer with $0.05 \mathrm{~m}^{3}$ used for casting lightweight pumice aggregate concrete. The following sequence of blending materials used: lightweight coarse aggregate and lightweight fine aggregate were mixed first for 30 seconds. Then, the half of concrete mixing water was added to the blending materials for 30 seconds if Sika level 100T added at the end of this stage during $30 \mathrm{sec}$. Next, the ordinary Portland cement added to the blended materials, and the process of mixing continued for another 30 seconds. Next, the remaining concrete mixing water added to the blending materials for 30 seconds. After that, silica fume was added to the mixed materials for another 30 seconds, as shown in Figure-2.

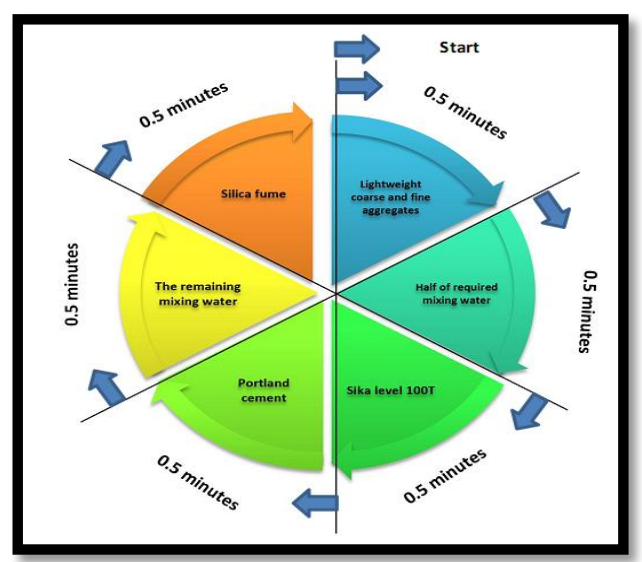

Fig-2: Mixing process of lightweight pumice concrete
The lightweight pumice aggregate concrete cast in the plywood mold in one layer, and each layer was vibrating from the outside of mold for 20 seconds. The molds used for checking the quality of the mix included six cubes for compression test and six prisms for the flexural test.

\section{TESTING OF CUBES FOR COMPRESSIVE STRENGTH}

Plywood cube molds (100 mm side length) used. During the casting of each beam, three cubes prepared. The concrete cubes stored in the curing basin for 7 and 28 days. Then, the concrete cubes were tested by the compressive machine, which had $3000 \mathrm{kN}$ capacity, with a loading rate of $0.4 \mathrm{MPa} / \mathrm{sec}$ [13]. Cube failures in compression test shown in Figure-3.

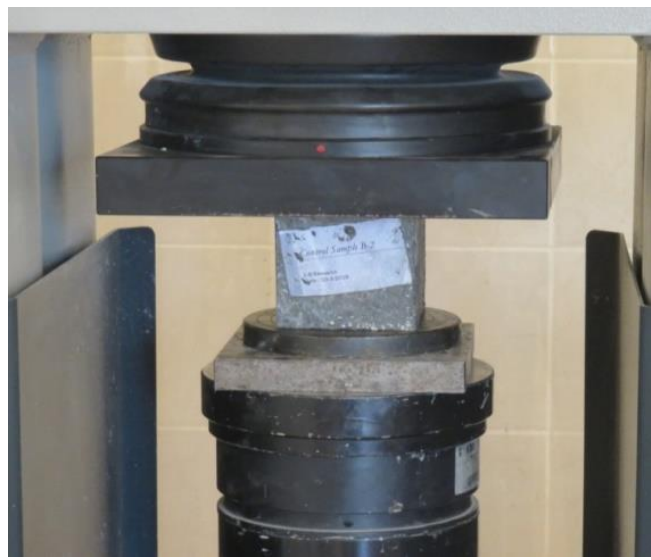

Fig-3: Compressive test of the cube 


\section{TESTING OF PRISMS FOR FLEXURAL STRENGTH}

The three-point flexural test was used to determine the modulus of rupture of lightweight pumice aggregate concrete [14]. According to ASTM C78, a $100 \times 100 \times 500 \mathrm{~mm}$ mold size was used. The molds were cast in one layer and vibrated for 20 seconds. After 24 hours of casting, the concrete prisms removed from the mold. After wet curing prisms for 7 and 28 days in the curing basin, the prisms were removed from the room and left at room temperature and humidity until the time of testing. The prisms were tested by the compressive machine, which had 100 $\mathrm{kN}$ capacity, with a $0.05 \mathrm{MPa} / \mathrm{min}$ loading rate, as shown in Figure-4.

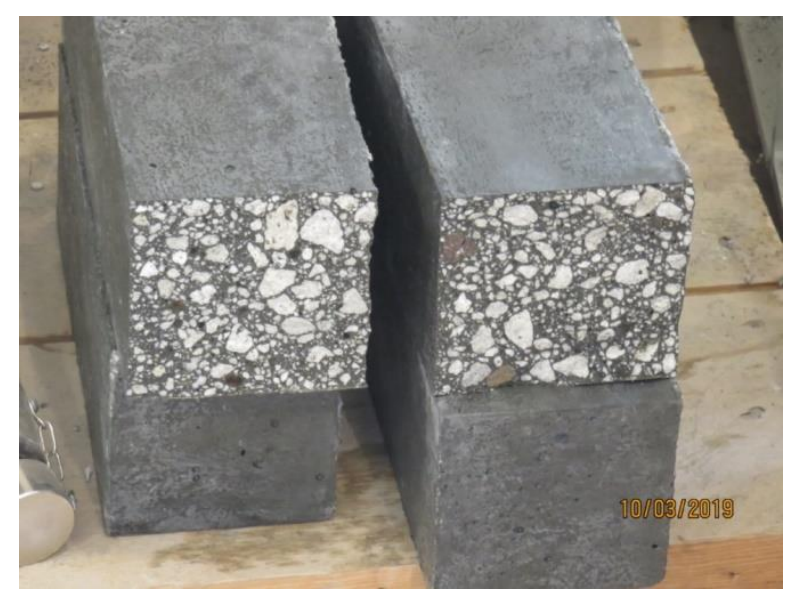

Fig-4: Sample of prism after flexural failure

\section{TESTING OF CUBES FOR DENSITY OF LIGHTWEIGHT CONCRETE}

Plywood cube molds (100 mm side length) used. Six cubes prepared for each mix. The concrete cubes stored in the curing basin for 7 and 28 days. Then, the concrete cubes were tested based on cube dimensions [15].

\section{RESULTS AND DISCUSSIONS}

This paper is a modest contribution to the ongoing discussions about the effect of silica fume solely, and the effect of coating pumice aggregate by a thin layer of Sika level 100T in concrete included silica fume. Besides, the properties of lightweight pumice aggregate concrete were measured based on ASTM and BSI.

\section{Effect of silica fume}

The inclusion of silica fume in lightweight pumice aggregate concrete are in good agreement with other studies which have shown that the inclusion of silica fume by $7.23 \%$ the compressive and flexural strengths, enhance up to $22.73 \%$ and $5.4 \%$, respectively as shown in Figures 5 and 6 . While the density of lightweight pumice aggregate concrete slightly influenced by the inclusion of silica fume due to a large porous on the surface of pumice aggregate, as shown in Figure-7.

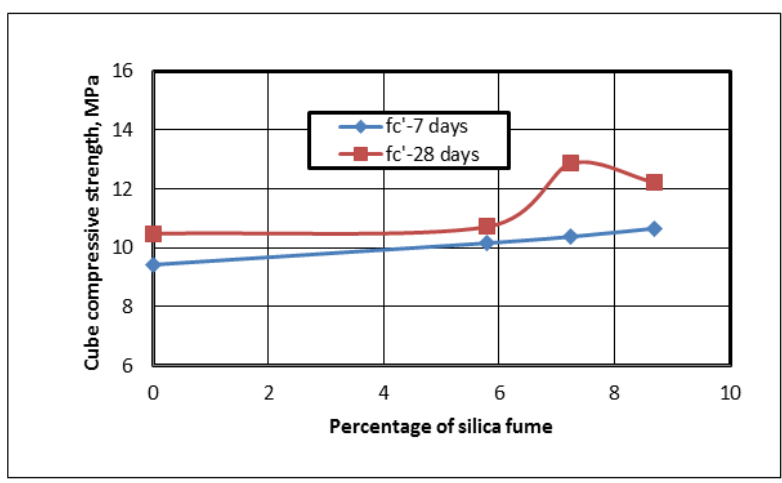

Fig-5: Compressive strength versus the percentage of silica fume

\section{Effect of Sika level 100T}

The originality of our solution lies in the fact that is producing thin cementitious coat by Sika level $100 \mathrm{~T}$ surrounding the pre-wetted pumice aggregate, which is possible practically. It improves both compressive and flexural strengths up to $34.57 \%$ and $25.72 \%$, respectively, due to adding Sika level $100 \mathrm{~T}$ by $9.6 \%$ of mass of cement, as shown in Figures 8 and 9. While the density of lightweight concrete is merely influenced by this coating due to large size of porous on the surface of pumice aggregate as shown in Figure 10.

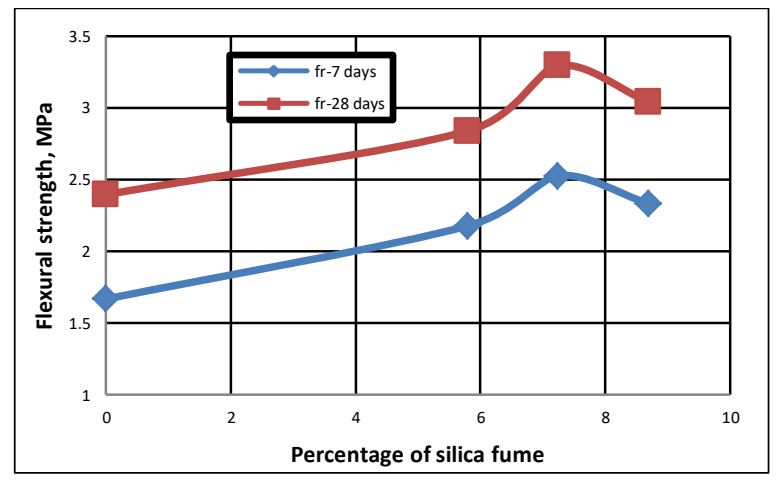

Fig-6: Flexural strength versus the percentage of silica fume

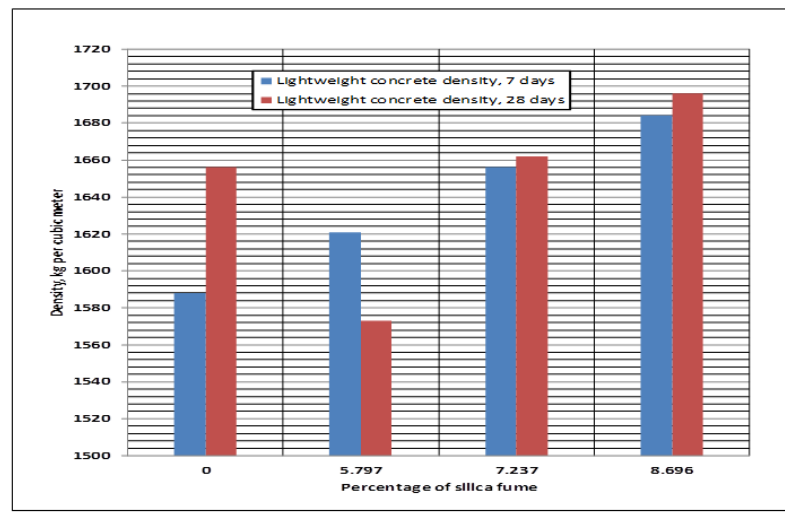

Fig-7: Density of lightweight concrete versus the percentage of silica fume 


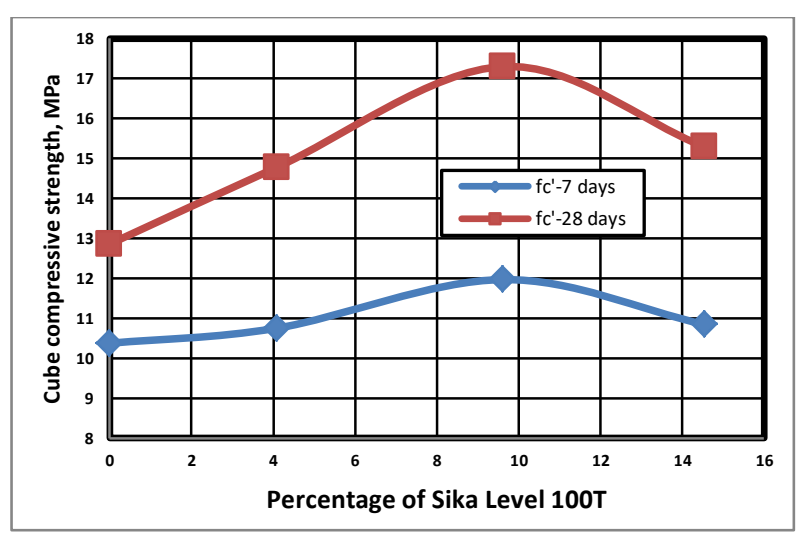

Fig-8: Compressive strength versus the percentage of Sika Level 100T

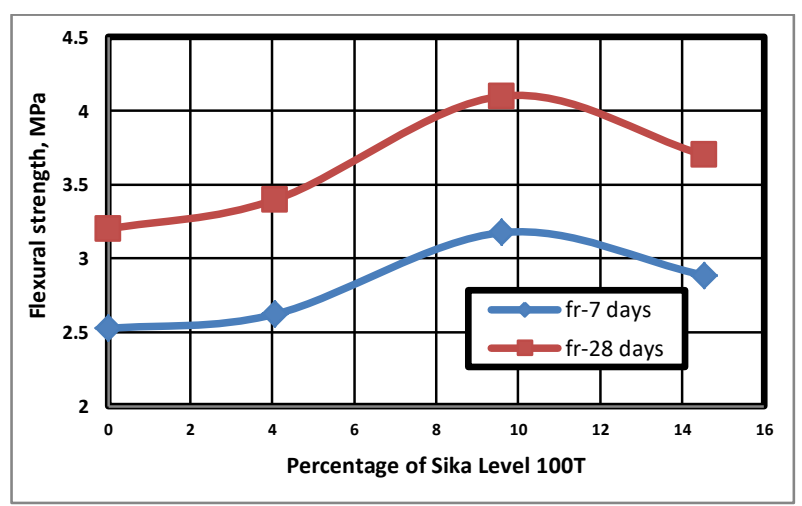

Fig-9: Flexural strength versus the percentage of Sika Level 100T

$$
f c_{\text {cube } 28 \text { days }}^{\prime}=0.799\left(0.873^{\frac{1}{S F}}\right)\left(S F^{-1.724}\right)
$$

Where,

fc': Cube compressive strength of lightweight pumice aggregate concrete at 28 days, MPa

SF: silica fume per binder materials in the mix

The following proposed model to predict the compressive strength has a correlation coefficient of $100 \%$ and standard error of 0 , which based on the 4 data and the model expressed as follows:

$$
f c^{\prime} \text { cube } 28 \text { days }=8.178+0.806(S L)-0.043(S L)^{2}
$$

Where,

SL: Sika Level per binder materials in the mix, \%

\section{STATISTICAL MODEL FOR FLEXURAL STRENGTH}

The Curve Expert software package version 1.3 was used to predict the effect of flexural strength of lightweight pumice aggregate concrete considering the percentage of silica fume and Sika level $100 \mathrm{~T}$ in the mix to binder ratio.

$$
f r=2.386-13.744 S F-59.50(S F)^{2}
$$

Where,

fr: Flexural strength of lightweight pumice aggregate concrete at 28 days, $\mathrm{MPa}$
The following proposed model for predicting the flexural strength of lightweight pumice aggregate concrete has a correlation coefficient of $100 \%$ and standard error of 0.0 , which based on the 4 data in this research, and the model expressed as follows: 
The following proposed model for predicting the flexural strength of lightweight pumice aggregate concrete has a correlation coefficient of $0.886 \%$ and standard error of 0.314 , which based on the 4 data in this research, and the model expressed as follows:

$$
f r=3.109+0.155 S L-0.007(S L)^{2}
$$

\section{CONCLUSIONS}

Based on the outcomes and the model proposed in this study for predicting the compressive strength in lightweight pumice aggregate concrete, the following conclusions could be carried out:

- The compressive strength of lightweight pumice aggregate concrete is found to be improved up to $22.73 \%$ due to addition of silica fume to the mix up to $7.23 \%$ from the control mix. In contrast, the compressive strength is enhanced up to $34.57 \%$ due to addition $9.6 \%$ of Sika level 100T if the percentage of silica fume has been constant.

- The flexural strength of lightweight pumice aggregate concrete is found to be improved up to $5.4 \%$ due to the addition of silica fume to the mix up to $7.23 \%$ from the control mix. While the flexural strength is enhanced up to $25.72 \%$ of Sika level 100T if the percentage of silica fume has been constant.

- The proposed models have a good agreement with the results of this research.

\section{ACKNOWLEDGMENT}

This research was supported by [University of Sulaimani]. We thank our colleagues from [Concrete Laboratory-College of Engineering] who provided insight and expertise that greatly assisted the research.

\section{REFERENCES}

1. Mehta, P. K., \& Monteiro, P. J. (2006). Concrete Microstructure, Properties and Materials. 3rd ed: McGraw-Hill.

2. ACI 213R. (2003). Guide for Structural Lightweight-Aggregate Concrete.

3. Miled, K., Le Roy, R., Sab, K., \& Boulay, C. (2004). Compressive behavior of an idealized EPS lightweight concrete: size effects and failure mode. Mechanics of materials, 36(11), 1031-1046.

4. Neville, A. M. (2011). Properties of concrete. 1st ed. England: Pearson Education Limited; 711-713.

5. Kitouni, S., \& Houari, H. (2013). Lightweight concrete with Algerian limestone dust: Part I:
Study on $30 \%$ replacement to normal aggregate at early age. Cerâmica, 59(352), 600-608.

6. Uğur, İ. (2003). Improving the strength characteristics of the pumice aggregate lightweight concretes. In 18th International Mining Congress and Exhibition at Turkey-IMCET.

7. Sivalingarao, N., \& Manju, N. (2016). A Brief Study on Mechanical Properties of Silica Fume Lightweight Aggregate (Pumice) Concrete. International Conference on Recent Innovations in Civil and Mechanical Engineering, CAM2K16: Journal of Mechanical and Civil Engineering (IOSR-JMCE), 66-71.

8. Mang'uriu, G. N., Mutku, R. N., Oyawa, W. O., \& Abuodha, S. O. (2012). Properties of Pumice Lightweight Aggregate. Civil and Environmental Research, 2(10):58-67.

9. Papanicolaou, C. G., \& Kaffetzakis, M. I. (2011). Lightweight aggregate self-compacting concrete: state-of-the-art \& pumice application. Journal of Advanced Concrete Technology, 9(1), 15-29.

10. Katkhuda, H., Hanayneh, B., \& Shatarat, N. (2009). Influence of Silica fume on High Strength Lightweight concrete. International Journal of Civil and Environmental Engineering, 3(10):40714.

11. Mohammadi, Y., Mousavi, S. S., Rostami, F., Danesh, A., \& Sarand, N. I. (2015). The effect of silica fume on the properties of self-compacting lightweight concrete. Current World Environment, 10(1):381-388

12. Chandra, S., \& Berntsson, L. (2002). Lightweight aggregate concrete Science, Technology, and Applications. Norwich, New York, U.S.A.: Noyes Publications; 407.

13. BS EN 12390-3. (2002). Testing hardened concrete-Part3: Compressive strength of test specimens. BRITISH STANDARD BSi. Part 3:18.

14. ASTM C78. (2010). Standard Test Method for Flexural Strength of Concrete (Using Simple Beam with Third-Point Loading). Annual Book of ASTM Standards. 4.02:3.

15. BS 1881-114. (2002). Testing concrete- Part 114: Methods for determination of density of hardened concrete. BRITISH STANDARD BSi. 12:12. 